\title{
Twenty-year survival post-liver transplant: challenges and lessons
}

\author{
Sung-Gyu Lee
}

Received: 13 November 2014/ Accepted: 27 February 2015/Published online: 28 March 2015

(C) Asian Pacific Association for the Study of the Liver 2015

\begin{abstract}
There have been numerous reports on survival outcomes after liver transplantation with short-term and mid-term follow-up. However, only a few reports are available for 20-year long-term survivors after liver transplantation. In Korea, the first successful deceased donor liver transplantation (DDLT) in a 13-year-old Wilson's disease patient was performed in 1988, and the first successful living donor liver transplantation (LDLT) in 9-month biliary atresia patient was performed in 1994. Because of the severe shortage of deceased donors and delayed launching of LDLT from December 1994, only 38 cases of liver transplantation (two pediatric LDLTs and 36 DDLTs) from 1988 to 1994 were included in this study (Strong and Fawcett, Hepatol Int 2015 [1]. doi:10.1007/ s12072-015-9617-1) to investigate more than 20-year survivors. Six adult recipients after DDLT and three pediatric recipients (one DDLT, two LDLTs) are alive now with normal liver function in Korea. Twenty-year survivors after DDLT and LDLT do not show that significant co-morbidities related to long-term immunosuppression and highdose indefinite HBIG monotherapy has shown the reliable modality to prevent HBV-reinfection for HBV-related liver transplant candidates.
\end{abstract}

Keywords 20-Year survivors - Liver transplantation . Korea

Although several authors have reported 5-year survival outcomes, little is known about long-term results in liver

S.-G. Lee $(\bowtie)$

Hepato-Biliary Surgery and Liver Transplantation, Department of Surgery, Asan Medical Center, Ulsan University College of Medicine, Seoul, Korea

e-mail: sglee2@amc.seoul.kr recipients surviving $\geq 20$ years. The author analyzed 20-year survivors after liver transplantation (LT) in Korea.

Since the first successful deceased donor liver transplantation (DDLT) in 1967 [2], this procedure has rapidly evolved from an experimental procedure to a standard therapeutic modality for end-stage liver diseases (ESLD) in Western countries. In Asia, the development of DDLT was seriously restricted by the severe shortage of deceased donor liver grafts, and the deceased donor allocation in Korea remained below 1.5 per million population per year in early 1990. In Korea, the first DDLT in a 13-year-old female child suffering from Wilson's disease with cerebral dysfunction was successfully performed from full-size liver donation of a 15-year boy with a brain tumor in 1988 by Professor ST Kim at Seoul National University. The recipient, now 39 years old, is alive with normal liver function and improved brain dysfunction. There was a 4-year silent period between the first DDLT and the second DDLT in 1992. In 1992, seven DDLTs were performed by three centers (three at Asan Medical Center, two at Seoul National University, and two at InJe University). Among seven recipients in 1992, one adult recipient (a 42-year-old male, HBV-LC) is alive with normal liver function (Table 1). Since LT has been known to be an optional standard treatment for patients with ESLD, the limited supply of deceased donor livers accelerated the application of living donor liver transplantation (LDLT). The first successful pediatric and adult LDLT in Korea were performed in December 1994 (9-month biliary atresia) and in February 1997 [a 37-year-old with HBV-cirrhosis and hepatocellular carcinoma (HCC)] at the Asan Medical Center, and they now have normal liver function. Our initial two consecutive pediatric recipients after LDLTs performed in December 1994 have since been alive for more than 20 years. In the 1990s, the hepatitis B virus 
Table 1 Demographic data of 12 adult recipients who underwent DDLT at the Asan Medical Center, Ulsan University from August 1992 to November 1994

\begin{tabular}{|c|c|c|c|c|c|c|}
\hline Patient & $\begin{array}{l}\text { Date of } \\
\text { operation }\end{array}$ & $\begin{array}{l}\text { Sex/age } \\
\text { at LT }\end{array}$ & Liver disease & Donor & $\begin{array}{l}\text { Urgency } \\
\text { category }\end{array}$ & Remarks \\
\hline \multicolumn{7}{|c|}{ Recipients surviving $>20$ years } \\
\hline OLT 3 & 19921009 & $\mathrm{M} / 42$ & HBV-LC & M/17 & 3 & Alive; longest adult survivor in Korea \\
\hline OLT 7 & 19940801 & $\mathrm{~F} / 21$ & Congenital hepatic fibrosis & $\mathrm{M} / 25$ & 3 & $\begin{array}{l}\text { Alive; re-DDLT for original disease } \\
\text { recurrence at } 2005\end{array}$ \\
\hline OLT 8 & 19940903 & $\mathrm{~F} / 22$ & Fulminant hepatic failure & $\mathrm{M} / 27$ & 6 & $\begin{array}{l}\text { Alive; KT (2014) for renal biopsy- } \\
\text { induced injury and subsequent CRF }\end{array}$ \\
\hline OLT 10 & 19941102 & $\mathrm{M} / 47$ & HBV-LC & $\mathrm{M} / 32$ & 3 & Alive \\
\hline \multicolumn{7}{|c|}{ Recipients survived $<20$ years } \\
\hline OLT 2 & 19920828 & $\mathrm{M} / 42$ & HBV-LC & $\mathrm{M} / 20$ & 3 & $\begin{array}{l}\text { Died } 8 \text { years after LT by HBV-recurrence } \\
\text { due to HBIG discontinuance }\end{array}$ \\
\hline OLT 5 & 19930715 & $\mathrm{~F} / 45$ & HBV-LC & $\mathrm{M} / 20$ & 4 & $\begin{array}{l}\text { Died } 17 \text { years after LT by myocardiac } \\
\text { infarction }\end{array}$ \\
\hline OLT 11 & 19941124 & $\mathrm{M} / 52$ & HBV-LC & $\mathrm{M} / 31$ & 3 & $\begin{array}{l}\text { Died } 2 \text { years after LT by toxic hepatitis } \\
\text { due to herb medicine (self-use) }\end{array}$ \\
\hline OLT 12 & 19941204 & $\mathrm{M} / 44$ & HBV-LC and HCC & $\mathrm{M} / 30$ & 3 & Died 6 years after LT by HCC recurrence \\
\hline \multicolumn{7}{|c|}{ Recipients with in-hospital mortality } \\
\hline OLT 1 & 19920821 & M/49 & HBV-LC and HCC & $\mathrm{M} / 43$ & 5 & Died of sepsis and HBV re-infection \\
\hline OLT 4 & 19930119 & $\mathrm{M} / 46$ & HBV-LC & $\mathrm{M} / 22$ & 3 & Died of PNF \\
\hline OLT 6 & $\begin{array}{l}19931030 \\
19931106 \text { (re-DDLT) }\end{array}$ & $\mathrm{M} / 49$ & HBV-LC and HCC & $\begin{array}{l}\mathrm{F} / 42 \\
\mathrm{M} / 38\end{array}$ & 6 & $\begin{array}{l}\text { Developed PNF/died of HA } \\
\text { pseudoaneurysm rupture }\end{array}$ \\
\hline OLT 9 & 19941006 & $\mathrm{~F} / 58$ & HBV-LC and HCC & $\mathrm{M} / 22$ & 3 & Died of HAT \\
\hline
\end{tabular}

$D D L T$ deceased donor liver transplantation, $O L T$ orthotopic liver transplantation, $H B V-L C$ hepatitis B liver cirrhosis, $K T$ kidney transplantation, $C R F$ chronic renal failure, $L T$ liver transplantation, $H B I G$ hepatitis B immunoglobulin

(HBV) carrier rate in the Korean population was near $8 \%$; hence, $\mathrm{HBV}$ has been a significant cause of ESLD and HCC. Meanwhile, the recurrent HBV-infection was one of the most lethal complications encountered in the liver transplant population, and strategies to prevent re-infection had been of limited utility in the early 1990s. Fibrosing cholestatic hepatitis often led to liver failure and death [3]. Active viral replication with detection of HBV-DNA or/ and $\mathrm{HBeAg}$, especially in Asian patients, had been considered a contraindication to LT in many American centers. In our series, approximately $87 \%$ of adult recipients were $\operatorname{HBsAg}(+)$, and a majority of them had active viral replication before DDLT. (However, at present, $\operatorname{HBsAg}(+)$ has decreased to $56 \%$ of our adult LT recipients by neonatal vaccination from 1994.) Antiviral drugs to HBV were not practical except passive immunoprophylaxis with antiHBV immunoglobulin (HBIG) injection. In 1992, the intravenous preparation of HBIG used in Europe was unavailable in Korea, instead, an intramuscular preparation (HEPA-BIG, Green Cross Company, Seoul, Korea) must be given either intramuscularly (which limited the dose that can be given) or intravenously with potential toxicities not yet identified. The most effective approach introduced by European Centers had been the use of long-term high-dose
anti-HBs Ig in the perioperative and postoperative periods (IV 10,000 IU during anhepatic phase, 10,000 IU daily for first post-LT 6 days, 10,000 IU weekly for first month, then $10,000 \mathrm{IU}$ monthly for first year, and boostered throughout the follow-up period when the titer of anti-HBs $\mathrm{Ab}$ was $<100$ IU/L in serum) $[4,5]$. The high-dose of antiHBs Ig required was extremely expensive ( $>2000$ US $\$$ per $10,000 \mathrm{IU})$ and must likely be given indefinitely to be effective. Only rich patients with HBV-ESLD and HCC could undergo LT by the high costs of HBIG (now, its cost is cheaper $<200$ US $\$$ by government insurance coverage). Intramuscular preparation of HBIG monotherapy had been used intravenously (infusion time 5-6 h long to avoid side effects as fever, neurologic symptoms, chest discomfort, etc.) with a high dose indefinitely in our institute [6], except the first OLT.

In Korea, the total number of adult liver transplant cases with more than 20-year follow-up by November 2014 (at the time of manuscript submission) were 32, and all were DDLTs performed from March 1992 to November 1994. There are six 20-year long-term adult survivors (four performed at the Asan Medical Center, one at the Seoul National University and one at the Catholic University St. Mary Hospital). Etiologies of LT of six 20-year adult 
survivors were two HBV-LC, two NBNC-LC, one congenital hepatic fibrosis and one fulminate hepatic failure (Table 2). Immunosuppresants were cyclosporine, azathioprine and steroid (tacrolimus has been available for patients from 1996 in Korea). At the Asan Medical Center, 13 DDLTs with full-size graft in 12 recipients were performed for seven HBV-LC, three HBV-LC and co-existing $\mathrm{HCC}$, one congenital hepatic fibrosis and one fulminant hepatic failure from August 1992 to November 1994 (Table 1$)$. Ten patients $(83 \%)$ were positive to HBsAg, and $9(90 \%)$ of these 10 had signs of active viral replication. Urgency category of LT was defined by UNOS sixtier classification system: (1) working or in school, (2) confined to home with self-care, (3) confined to home and requiring professional care, (4) hospital bound but not in ICU, (5) ICU bound without ventilator support, and (6) in ICU on ventilator and usually unconscious. Liver harvesting was carried out by standard technique with preservation of HTK solution (Custodiol, Germany). As shown in Table 1, the in-hospital mortality was high (33\%) during the learning period; causes of death were one sepsis and HBV re-infection by low-dose HBIG, two primary nonfunction of liver grafts (PNF) by long $(>12 \mathrm{~h}$ ) cold ischemia time (because single same surgeon had performed both donor and recipient operations), and one HAT (hepatic artery thrombosis) by lack of technical skills and experiences (Table 1). But, with increasing experience, the in-hospital mortality had decreased to $17 \%$ (one death of six DDLTs) in 1994 (the third year of OLT launching at the Asan Medical Center). After a 2-year learning period in 1992 and 1993 with improved survival outcomes, the requirement for DDLT had increased from the patient population and medical society. As a breakthrough to activate the OLT program, pediatric and adult LDLT were initiated in 1994 and 1997 with success in Korea [7]. In addition, nationwide efforts to promote the deceased organ donation has increased the numbers of DDLT (Fig. 1).

There have been numerous reports on survival outcomes after LT with short- and mid-term follow-up. However, only a few reports are available for long-term follow-up
[8]. The remaining eight adult recipients who survived $>60$ days after DDLT have been followed up from 2 to 22 years in our institute; noticeably, two OLT patients who had carried out normal liver function with a high-dose HBIG for 6 years died of HBV re-infection 2 years after HBIG discontinuance for its high cost (Table 1). We learned that passive immunoprophylaxis with anti-HBs Ig should be administered indefinitely with a high-dose (>10,000 IU). All co-existing HCC in HBV-LC patients demonstrated the "beyond Milan Criteria"; one who survived the operation died of HCC recurrence 6 years after LT (Table 1). Four 20-year adult survivors are now carrying normal activity and liver function, although OLT 7 underwent re-DDLT for original disease recurrence 11 years after primary LT, and OLT 8 underwent kidney transplant for CRF (chronic renal failure) caused by iatrogenic bilateral renal-biopsy induced hemorrhagic injury 10 years after LT (Table 1). Acute rejection developed in 1 recipient (OLT 7) by noncompliance of immunosuppressant 2 years after LT, but she was rescued by tacrolimus switching in 1996. Graft loss from acute or chronic rejection has not emerged. Early and late biliary strictures frequently seen in adult LDLT has not developed in all recipients who underwent DDLT. Vascular complications such as HAT, PV stenosis and hepatic venous outflow stenosis did not occur in our 12 adult DDLT and two pediatric LDLT recipients, except one HAT of OLT 9 after DDLT who demonstrated a very small-sized $(<3 \mathrm{~mm}$ caliber) proper hepatic artery with conventional anastomotic technique. HAT was preventable if a microscopic anastomotic technique was used as in LDLT, but microscopic HA anastomosis was initiated from December 1994 with LDLT. HBV re-infection has not been shown in all recipients who received the indefinite and high-dose HBIG.

\section{Summary}

This analysis demonstrates that long-term survivors do not show the significant co-morbidities related to long-term

Table 2 Analysis of adult 20-year survivors after liver transplantation in Korea

\begin{tabular}{|c|c|c|c|c|c|}
\hline Patient number & Year of LT & Sex/age at LT & Liver disease & Institute & Remarks \\
\hline 1 & 1992 & $\mathrm{M} / 42$ & HBV-LC & $\mathrm{AMC}$ & 22 years, alive \\
\hline 2 & 1993 & $\mathrm{M} / 31$ & NBNC-LC & $\mathrm{CMC}$ & 21 years, alive \\
\hline 3 & 1994 & $\mathrm{~F} / 21$ & Congenital hepatic fibrosis & AMC & 20 years, alive \\
\hline 4 & 1994 & $F / 22$ & Fulminant hepatic failure & $\mathrm{AMC}$ & 20 years, alive \\
\hline 5 & 1994 & $\mathrm{M} / 47$ & HBV-LC & AMC & 20 years, alive \\
\hline 6 & 1994 & $\mathrm{M} / 47$ & NBNC-LC & SNU & 20 years, alive \\
\hline
\end{tabular}

$H B V-L C$ hepatitis B liver cirrhosis, $N B N C-L C$ non-B, non-C liver cirrhosis, $A M C$ Asan Medical Center, $C M C$ Catholic University St. Mary Hospital, SNU Seoul National University 


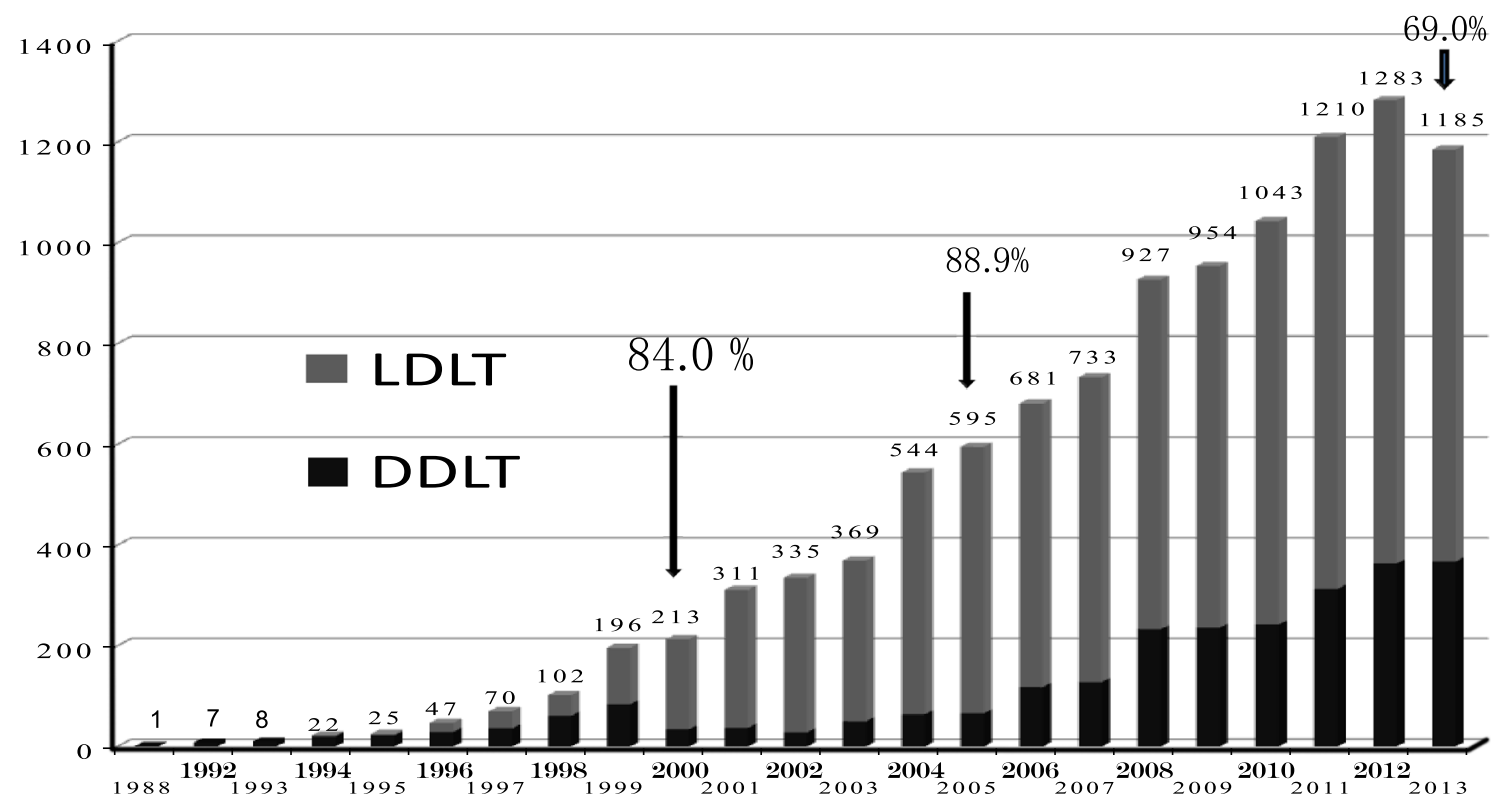

Fig. 1 Annual number of liver transplantations in Korea (from KONOS annual report 2013). Living donor liver transplantation (LDLT) accounted for $76.5 \%$ of all LT in Korea. The first deceased donor liver transplantation (DDLT) was performed in 1988. The second DDLT was performed in 1992. The first LDLT was performed in 1994 for children. In 1997, adult LDLT was successfully initiated, and then the LDLT number had increased. In 2000, the cadaveric liver graft from a decreased donor was limited even though the OLT

immunosuppression, that graft loss from acute or chronic rejection has emerged as a rarity, and that high-dose indefinite HBIG monotherapy is the reliable modality to prevent HBV-reinfection.

Compliance with ethical requirements and Conflict of interest Sung-Gyu Lee states that he has complied with all ethical requirements during the preparation of this manuscript. Sung-Gyu Lee declares that he has no conflict of interest.

\section{References}

1. Strong R, Fawcett J. 20-year survival post-liver transplant: much more is needed! Hepatol Int 2015. doi:10.1007/s12072-015-9617-1

2. Starzl TE, Iwatsuki S, Van Thiel DH, et al. Evolution of liver transplantation. Hepatology 1982;2:614-636 number exceeded $>200$ cases per year, showing that LDLT occupied $8.40 \%$ of the total orthotopic liver transplantation (OLT). In 2005, the LDLT still occupied $88.9 \%$ of all OLT because of deceased donor organ shortage. But, from 2006, deceased organ donation rate has progressively increased to $>5$ per million population. In 2013, the proportion of LDLT to total OLT had decreased to $69.0 \%$, with more opportunity of DDLT for high-urgency patients. KONOS Korean network of organ sharing

3. Todo S, Demetris AJ, Van Thiel D, Teperman L, Fung JJ, Starzl TE. Orthotopic liver transplantation for patients with hepatitis B virus-related liver disease. Hepatology 1991;13:619-626

4. Lauchart W, Müller R, Pichlmayr R. Long-term immunoprophylaxis of hepatitis B virus reinfection in recipients of human liver allografts. Transplant Proc 1987;19:4051-4053

5. Samuel D, Bismuth A, Mathieu D, et al. Passive immunoprophylaxis after liver transplantation in HBsAg-positive patients. Lancet 1991;337:813-815

6. Lee SG, Lee YJ, Kwon TW, Park KM, Choi KM, Min PC, et al. Unlimited-term passive immunoprophylaxis after liver transplantation in HBsAg-positive patients. Transplant Proc 1996;28:1176-1177

7. Moon DB, Lee SG, Hwang S, et al. Toward more than 400 liver transplantations a year at a single center. Transplant Proc 2013; 45:1937-1941

8. Jain A, Reyes J, Kashyap R, Dodson SF, Demetris A, Ruppert K, et al. Long-term survival after liver transplantation in 4,000 consecutive patients at a single center. Ann Surg 2000;232:490-500 